\title{
Association between the APOE $\varepsilon 4$ Allele and Late-Onset Alzheimer's Disease in an Ecuadorian Mestizo Population
}

\author{
Stefany Montufar, ${ }^{1}$ Cristian Calero, ${ }^{2}$ Rodrigo Vinueza, ${ }^{1}$ Patricio Correa, ${ }^{2}$ \\ Andrea Carrera-Gonzalez, ${ }^{1}$ Franklin Villegas, ${ }^{1}$ Germania Moreta, ${ }^{3}$ and Rosario Paredes ${ }^{1}$ \\ ${ }^{1}$ Hospital de Especialidades FFAA, Quito, Pichincha, Ecuador \\ ${ }^{2}$ Hospital Carlos Andrade Marín, Quito, Pichincha, Ecuador \\ ${ }^{3}$ Hospital Metropolitano, Quito, Pichincha, Ecuador \\ Correspondence should be addressed to Stefany Montufar; stefymontufar@hotmail.com
}

Received 4 July 2017; Revised 27 September 2017; Accepted 26 October 2017; Published 4 December 2017

Academic Editor: Francesco Panza

Copyright (C) 2017 Stefany Montufar et al. This is an open access article distributed under the Creative Commons Attribution License, which permits unrestricted use, distribution, and reproduction in any medium, provided the original work is properly cited.

\begin{abstract}
Alzheimer's disease (AD) is the most common neurodegenerative disease. It has two main pathological hallmarks: amyloid plaques and neurofibrillary tangles. The APOE $\varepsilon 4$ allele has been recognized as the strongest genetic risk factor for late-onset Alzheimer's disease (LOAD) in several populations worldwide, yet the risk varies by region and ethnicity. The aims of this study were to describe APOE allele and genotype frequencies and examine the relationship between the APOE $\varepsilon 4$ allele and LOAD risk in an Ecuadorian Mestizo population. We carried out a case-control study comprising 56 individuals clinically diagnosed with probable AD ( $\geq 65$ years of age) and 58 unrelated healthy control subjects ( $\geq 65$ years of age). Genotyping was performed using the real-time PCR method. Our data showed that allelic and genotypic frequencies follow the trends observed in most worldwide populations. We also found a high-risk association between APOE $\varepsilon 4$ allele carriers and LOAD (OR $=7.286 ; 95 \% \mathrm{CI}=2.824-18.799 ; p<0.001)$. Therefore, we concluded that APOE $\varepsilon 4$ must be considered an important genetic risk factor for LOAD in the Ecuadorian Mestizo population. Additionally, we suggest that in mixed populations the effects of admixture and ethnic identity should be differentiated when evaluating genetic contributions to Alzheimer's disease risk.
\end{abstract}

\section{Introduction}

Alzheimer's disease (AD) has emerged as the most prevalent form of late-life mental failure in humans, accounting for about $60-80 \%$ of dementia cases [1]. Alzheimer's Disease International (ADI) estimated that 46.8 million people worldwide were living with dementia in 2015 and predicted that this figure would reach 131.5 million in 2050 [2]. In Latin America, due to demographic and health transitions as well as low socioeconomic levels, it is expected that the number of people with dementia will rise from 7.8 million in 2013 to over 27 million by $2050[3,4]$. The analysis of eight population studies conducted in Brazil, Cuba, Chile, Peru, and Venezuela showed that the global prevalence of dementia in Latin America has reached 7.1\%, with AD being the most frequent type [5]. In Ecuador, there are no official data of prevalence or incidence of dementia.
$\mathrm{AD}$ is a progressive and irreversible neurodegenerative disorder characterized by a decline in memory, language, problem-solving, and other cognitive skills that affect an individual's ability to perform daily activities [1]. The key neuropathological features of $\mathrm{AD}$ are extracellular plaques composed of $\beta$-amyloid peptides $(\mathrm{A} \beta)$ and intracellular neurofibrillary tangles (NFTs), consisting of hyperphosphorylated tau proteins $[6,7]$. Other neuropathological changes are synapse and neuronal loss, cerebral atrophy, gliosis, white matter degeneration, granulovacuolar degeneration, cerebral amyloid angiopathy (CAA), and other protein aggregates (TAR DNA-binding protein 43-immunoreactive inclusions, Lewy bodies, and actin-immunoreactive Hirano bodies) [7].

Based on the age of onset, $\mathrm{AD}$ is classified into two types: early-onset $\mathrm{AD}$ (EOAD, onset $<65$ years of age) accounting for $1-5 \%$ of all cases and late-onset $\mathrm{AD}$ (LOAD, onset $\geq 65$ years of age) accounting for $>95 \%$ of them [8]. 
Three dominant inherited mutations in the genes amyloid precursor protein (APP), presenilin-1 (PS1), and presenilin-2 (PS2), which increase the production of amyloid-beta $(\mathrm{A} \beta)$ peptides, have been linked to $\operatorname{EOAD}[9,10]$. Conversely, LOAD has been identified to be more complex involving multiple susceptibility genes and environmental factors [11]. Genetically, the APOE $\varepsilon 4$ allele has been recognized as the strongest risk factor for LOAD [12-14].

Apolipoprotein E (APOE) is a glycoprotein of 299 amino acids with an estimated molecular mass of $\sim 34 \mathrm{kDa}$ that is involved in cholesterol transport and encoded by the APOE gene located in the long arm of the chromosome 19q13.2 [15]. The human APOE gene exists as three polymorphic alleles- $-\varepsilon 2, \varepsilon 3$, and $\varepsilon 4-$ which differ by cysteine and arginine amino acids at residues 112 and 158, with $\varepsilon 2$ (cys112, cys158), $\varepsilon 3$ (cys112, $\arg 158)$, and $\varepsilon 4$ (arg112, $\arg 158)[16]$.

The APOE $\varepsilon 4$ allele has been related to earlier onset as well as higher risk for $\mathrm{AD}$, and individuals with two copies of the APOE $\varepsilon 4$ allele have a higher risk and earlier onset than heterozygous subjects [17]. Several studies have suggested mechanisms that could explain APOE $\varepsilon 4$ allele's contribution to the pathogenesis of $\mathrm{AD}$. These include the modulation of the deposition and clearance of $\mathrm{A} \beta$, formation of plaques, impairment of the antioxidative defense system, dysregulation of the neuronal signaling pathways, disruption of cytoskeletal structure and function, and increased phosphorylation of tau with formation of neurofibrillary tangles [18].

Few APOE studies have been conducted in Latin America, and in Ecuador only two previous studies have investigated that gene. The first study evaluated frequencies of APOE genotypes and alleles in a population of Cayapas from Esmeraldas $(n=96)$ [19]. However, even though Cayapa Indians are part of the indigenous population living in Ecuador, Mestizos are the most numerous ethnic group accounting for approximately $60 \%$ of the total population. Ecuadorian Mestizos can be considered a trihybrid population resulting from the admixture of Amerindian, European, and African populations, having estimated average proportions of $\sim 73$, $\sim 19$, and $\sim 8 \%$ in autosomal cells, respectively [20]. The second study evaluated the association between APOE $\varepsilon 4$ and AD in a sample consisting of healthy $(n=39)$ and affected $(n=39)$ individuals from different provinces of Ecuador. Nevertheless, the ethnic composition was not detailed and no significant association was found in that study probably due to the limited sample size [21].

Therefore, the aims of this study were to describe APOE genotype and allele frequencies in a control-case study and to determine the relationship between APOE $\varepsilon 4$ allele carriers and the risk of developing LOAD in an Ecuadorian Mestizo population.

\section{Materials and Methods}

2.1. Study Population. Subjects were recruited from the Hospital Carlos Andrade Marín in Quito, Ecuador, from September 2014 until May 2015. All participants were ethnic Mestizo Ecuadorians aged 65 and older.
The case subjects consisted of 56 unrelated patients with a clinical diagnosis of probable $\mathrm{AD}$ established by a neurologist according to the National Institute on Aging and the Alzheimer's Association (NIA-AA) criteria [37]. All the patients were subjected to the following procedures: (1) a neurological examination, which included a physical examination and a review of medical history; (2) a computerized axial tomography (CAT), to confirm hippocampal atrophy and exclude hydrocephalus, cerebrovascular disorders, or intracranial mass; (3) a Mini-Mental State Examination (MMSE) test score of 24 or less; (4) laboratory tests (blood count, blood chemistry, alanine transaminase (ALT), aspartate transaminase (AST), vitamin B12 level, folic acid level, and thyroid-stimulating hormone (TSH)) to exclude other diseases than $\mathrm{AD}$ that potentially would cause symptoms of dementia; (5) an exclusion of secondary causes of dementia such as depressive disorder, bipolar disorder, schizophrenia, substance use disorder, mental retardation, history of traumatic brain injury, or another neurologic disease.

The control subjects consisted of 58 healthy unrelated volunteers with no signs of psychiatric or neurological impairment, based on clinical examinations which included an MMSE score of 27 or higher.

All procedures were carried out with informed and signed consent from patients or suitable proxies and healthy volunteers. This study was approved by the Central University Bioethics Committee (UCE-COBI) and was performed in accordance with the Ethical Standards of the Declaration of Helsinki.

2.2. Genotyping. Genomic DNA extraction was carried out from peripheral blood samples using the High Pure PCR Template Preparation Kit (Roche Diagnostics GmbH, Mannheim, Germany) in accordance with the manufacturer's protocol.

Real-time PCR (RT-PCR) and genotyping were performed on the LightCycler 2.0 platform, software version 4.1, using the fluorescent resonance energy transfer (FRET) technique (Roche Diagnostics $G m b H$, Mannheim, Germany) with predesigned primers and probes from the LightMix ${ }^{\circledR}$ ApoE C112R R158C kit (TIB MOLBIOL GmbH, Berlin, Germany).

2.3. Statistical Analyses. Deviation from Hardy-Weinberg equilibrium (HWE) of APOE genotype and alleles was calculated with the Pearson chi-square statistical test in both the case and the control populations.

Statistical analyses were performed using the SPSS software, version 22 (IBM-SPSS Inc., Chicago, IL). Categorical variables were described through frequencies and percentages, and quantitative variables were described using means and standard deviations.

Variables were compared between the case and control groups using the $t$-test for quantitative variables and chisquare test with the Yates correction applied or Fisher's exact test for categorical variables. The statistical significance was set at 0.05 for each analysis. Odds ratio (OR) and 95\% confidence intervals (CI) were calculated to determine the strength of association between APOE $\varepsilon 4$ carriers and the risk of developing LOAD. 
TABLE 1: Demographic and clinical characteristics.

\begin{tabular}{|c|c|c|c|}
\hline & $\begin{array}{c}\text { LOAD cases } \\
n=56\end{array}$ & $\begin{array}{c}\text { Controls } \\
n=58\end{array}$ & $p$ \\
\hline Gender, female (\%) & $30(53.6)$ & $31(53.4)$ & $1.00^{\mathrm{aNS}}$ \\
\hline Age $\pm S D$, years & $78.04 \pm 6.32$ & $76.62 \pm 7.07$ & $0.263^{\mathrm{NS}}$ \\
\hline Smoking, yes (\%) & $18(32.1)$ & $13(22.4)$ & $0.309^{\mathrm{a} N S}$ \\
\hline Hypertension, yes (\%) & $27(48.2)$ & $33(56.9)$ & $0.459^{\mathrm{a} \mathrm{NS}}$ \\
\hline Diabetes, yes (\%) & $8(14.3)$ & $7(12.1)$ & $0.942^{\mathrm{aNS}}$ \\
\hline $\mathrm{MMSE} \pm \mathrm{SD}$, score & $18.07 \pm 5.24$ & $28.28 \pm 1.25$ & $<0.001^{*}$ \\
\hline Education \pm SD, years & $10.27 \pm 4.83$ & $10.38 \pm 4.24$ & $0.896^{\mathrm{NS}}$ \\
\hline
\end{tabular}

${ }^{\text {a } C o r r e c t e d ~ b y ~ Y a t e s ; ~ N S: ~ n o n s i g n i f i c a n t ; ~ * ~ s i g n i f i c a n t ; ~ S D: ~ s t a n d a r d ~ d e v i a t i o n ; ~ M M S E: ~ M i n i-M e n t a l ~ S t a t e ~ E x a m i n a t i o n . ~}$

TABLE 2: APOE allele and genotype frequencies in case and control subjects.

\begin{tabular}{|c|c|c|}
\hline Genotypes & $\begin{array}{c}\text { LOAD cases }(\%) \\
n=56\end{array}$ & $\begin{array}{c}\text { Controls (\%) } \\
n=58\end{array}$ \\
\hline$\varepsilon 3 \varepsilon 3$ & $27(48.2)$ & $47(81.0)$ \\
\hline$\varepsilon 3 \varepsilon 4$ & $17(30.4)$ & $6(10.3)$ \\
\hline$\varepsilon 4 \varepsilon 4$ & $10(17.9)$ & $0(0.0)$ \\
\hline$\varepsilon 2 \varepsilon 4$ & $1(1.8)$ & $1(1.7)$ \\
\hline$\varepsilon 2 \varepsilon 3$ & $1(1.8)$ & $4(6.9)$ \\
\hline Alleles & $\begin{array}{c}\text { LOAD cases }(\%) \\
n=112\end{array}$ & $\begin{array}{c}\text { Controls (\%) } \\
n=116\end{array}$ \\
\hline$\varepsilon 3$ & $72(64.3)$ & $104(89.7)$ \\
\hline$\varepsilon 4$ & 38 (33.9) & $7(6.0)$ \\
\hline$\varepsilon 2$ & $2(1.8)$ & $5(4.3)$ \\
\hline
\end{tabular}

\section{Results}

3.1. Demographic Description. A total of 114 participants were recruited, including 56 LOAD patients (mean age: $78.04 \pm$ $6.32 ; 53.6 \%$ females) and 58 healthy controls (mean age: $76.62 \pm 7.07 ; 53.4 \%$ females). Demographic and clinical data are summarized in Table 1 . There were no statistical differences in gender $(p=1.000)$, age $(p=0.263)$, smoking $(p=0.309)$, hypertension $(p=0.459)$, diabetes $(p=$ $0.942)$, and years of education $(p=0.896)$ between the two groups. As expected, the MMSE score in LOAD patients was significantly lower when compared with the control subjects' score $(p<0.001)$.

3.2. Allele and Genotype Frequency Distributions of APOE Polymorphisms. Analysis of APOE allele frequency data revealed that the case and control populations were in HardyWeinberg equilibrium. The distributions of each allele and genotype frequency are shown in Table 2.

APOE $\varepsilon 4$ allele frequencies were greater for patients with LOAD (33.9\%) than for control subjects (6.0\%). Furthermore, the statistical analysis showed that being a carrier of at least one APOE $\varepsilon 4$ allele seems to be a significant risk factor for LOAD $(\mathrm{OR}=7.286 ; 95 \% \mathrm{CI}=2.824-18.799 ; p<0.001)$ (Table 3).

\section{Discussion}

Alzheimer's disease represents one of the greatest global health problems of this century. Not only is it responsible for several deaths, but also it contributes to the increase in cases of poor health and disability [1]. Therefore, AD has become an epidemic affecting individuals and public health systems and, as yet, its current and future impacts have been underestimated [38].

Although associations between the APOE $\varepsilon 4$ allele and $\mathrm{AD}$ risk have been replicated in several populations, the frequencies of the three APOE alleles and the association of APOE $\varepsilon 4$ exposure with $\mathrm{AD}$ are highly variable among different populations [22, 39-41]. Additionally, previously published studies indicate that ethnicity, genetic, and environmental factors all contribute to $\mathrm{AD}$ risk [11, 42]. Thus, it is important to study the nature of this association in the specific population of interest.

The present study describes the APOE allele and genotype frequencies of 56 LOAD patients and 58 healthy control individuals in a Mestizo population from Ecuador and their association with LOAD. This is the first report that shows a significant risk association between APOE $\varepsilon 4$ carriers and LOAD in an Ecuadorian population. 
TABLE 3: Risk association between APOE and LOAD.

\begin{tabular}{lccc}
\hline Genotypes & $p$ & OR & $95 \%$ CI \\
\hline Non- $\varepsilon 4$ carriers & & $1^{\mathrm{R}}$ & $7.286^{*}$ \\
$\varepsilon 4$ carriers & $<0.001^{*}$ & $2.824-18.799$ \\
\hline
\end{tabular}

${ }^{\mathrm{R}}$ Reference; ${ }^{*}$ significant; OR: odds ratio; CI: confidence interval.

The distribution observed in the healthy control individuals showed that the most frequent APOE allele was $\varepsilon 3$ (89.7\%), followed by $\varepsilon 4(6.0 \%)$ and $\varepsilon 2(4.3 \%)$. Regarding genotypes, the $\varepsilon 3 \varepsilon 3$ genotype has the most common distribution $(81.0 \%)$, followed by $\varepsilon 3 \varepsilon 4$ (10.3\%), $\varepsilon 2 \varepsilon 3$ (6.3\%), and $\varepsilon 2 \varepsilon 4(1.7 \%)$. These allele and genotype frequencies maintain the trends described in most healthy control populations worldwide such as Caucasians, African Americans, Hispanics, and Japanese [22, 23]. Compared with other Latin American countries, the trends observed are consistent with those previously reported in samples from Ecuadorian and Peruvian Mestizo populations [21, 43] and with South American native populations from Argentina, Brazil, and Paraguay [44]. However, our findings differ from those observed in the Ecuadorian Cayapa population whose trend was $\varepsilon 3 \varepsilon 3>\varepsilon 3 \varepsilon 4$ $>\varepsilon 4 \varepsilon 4$ [19]. This difference could be attributed to the fact that Cayapas are an ethnic homogeneous indigenous population that has adapted to a series of catastrophic changes for at least 500 years without a significant admixture from either European- or African-derived settlements adjacent to tribal communities [45].

In our study, no subject bore the rare $\varepsilon 2 \varepsilon 2$ genotype which is concordant with previous studies in samples from Ecuadorian [16, 18], Mexican [46], Cuban [27], Colombian $[36,47]$, and Peruvian [43] populations. In addition, several studies suggest that the APOE $\varepsilon 2$ allele is present at very low frequencies or absent in groups that populated the Americas in prehistoric times $[44,46,48,49]$. De Andrade et al. (2000) proposed two possible explanations for these observations: (a) the APOE $\varepsilon 2$ allele was present in the founding native American populations at very low frequencies and either was lost from some groups during the process of tribalization or was not identified due to restricted sample sizes; (b) the presence of the APOE $\varepsilon 2$-allele is due to mixing with nonIndians [48].

Concerning the $\varepsilon 4 \varepsilon 4$ genotype, it was only found within the case group. Correspondingly, a large meta-analysis has shown that the $\varepsilon 4 \varepsilon 4$ genotype is found at very low frequencies in most healthy control populations worldwide: Caucasian (1.8\%), African American (2.1\%), Hispanic (1.9\%), and Japanese $(0.8 \%)$ [22].

We observed a higher frequency of the APOE $\varepsilon 4$ allele in the LOAD cases compared to the healthy control subjects $(33.9 \% / 6.0 \%=5.7)$. This coefficient is higher than the values reported worldwide in a large meta-analysis in Caucasian $(36.7 \% / 13.6 \%=2.7)$, African American $(32.2 \% / 19.0 \%=1.7)$, Hispanic $(19.2 \% / 11.0 \%=1.7)$, and Japanese $(27.8 \% / 8.9 \%=$ 3.1) populations [22]. Furthermore, it is higher than those previously described in other Latin American populations as is shown in Table 4. The low APOE $\varepsilon 4$ allele frequency in our control group could be because of the high LOAD risk it may be conferring in Ecuadorian population, making it less likely to be found in healthy individuals. It is worth mentioning that $12.0 \%$ of our control population had APOE genotypes carrying $\varepsilon 4$ allele $(\varepsilon 3 \varepsilon 4, \varepsilon 2 \varepsilon 4)$ and $50.0 \%$ of LOAD patients had APOE genotypes not carrying $\varepsilon 4$ allele $(\varepsilon 3 \varepsilon 3, \varepsilon 2 \varepsilon 3)$. This observation confirms that although the APOE $\varepsilon 4$ allele is confirmed as a risk factor for $\mathrm{AD}$, it is neither necessary nor sufficient to develop the disease, so there are probably other factors acting $[42,50,51]$.

Genotype analyses revealed a significant association between APOE $\varepsilon 4$ allele carriers and LOAD (OR = 7.286; 95\% $\mathrm{CI}=2.824-18.799 ; p<0.001)$. These findings suggest that APOE $\varepsilon 4$ indeed increases the risk of developing LOAD in the Ecuadorian Mestizo population, which is consistent with several studies $[13,22,41]$. The substantial risk for LOAD conferred by the APOE $\varepsilon 4$ allele for Ecuadorians in this study contrasts with the nonexistent risk of LOAD previously reported [21]. Nevertheless, even though the previous study did not reveal a significant association between APOE $\varepsilon 4$ allele carriers and LOAD, a noticeable difference between case and control groups was still observed in that study.

A low or nonexistent risk has been reported for "Hispanics" in worldwide studies where the majority of the individuals were of Caribbean origin [23], or of unspecified composition $[22,24]$. However, when analyzing the risk per country in Latin Americans, it seems to be heterogeneous as is shown in Table 4. In Mexico, two studies have reported a lack of association between APOE $\varepsilon 4$ allele carriers and LOAD, yet a small AD sample size (49 and 28 patients, resp.) should be mentioned as an important limitation in those studies $[25,26]$. In Cuba, a first study including patients with probable $\mathrm{AD}$ diagnosis showed an increased risk for $\mathrm{LOAD}$ in $\varepsilon 4$ carriers $(\mathrm{OR}=4.33$; $\mathrm{IC}=1.27-14.79$ ) [44]. Then, a second study confirmed that risk in a larger sample size; however, the patients included both probable and possible $\mathrm{AD}$ diagnosis and the association observed was lower $(\mathrm{OR}=2.47$; IC $=1.96-3.12)$ [28]. In Brazil, two independent studies, predominantly composed of individuals with European ethnic background, reported similar risks to each other for LOAD in $\varepsilon 4$ carriers $(\mathrm{OR}=3.63$; $\mathrm{IC}=2.19-6.03$ and $\mathrm{OR}=4.35 ; \mathrm{IC}=2.45-7.78)[24,25]$. Besides, the risk found in a small sample size (cases $=45$, controls $=45)$ from Argentina was similar to those reported in Brazilians $(\mathrm{OR}=$ 3.33; IC $=1.20-9.02$ ) [31]. Similarly, a moderate association has been reported in Venezuela [32, 33] and Chile [34]. In Colombia, the risks found are higher than those reported in the other Latin American countries [35, 36]. Particularly, the risk observed in our study between APOE $\varepsilon 4$ allele carriers and LOAD is similar to that found in the Colombian study with patients diagnosed with probable AD $(\varepsilon 4$ carriers: OR $=7.4 ; 95 \% \mathrm{CI}=2.5-22.0)$ [36]. This similarity may be due 


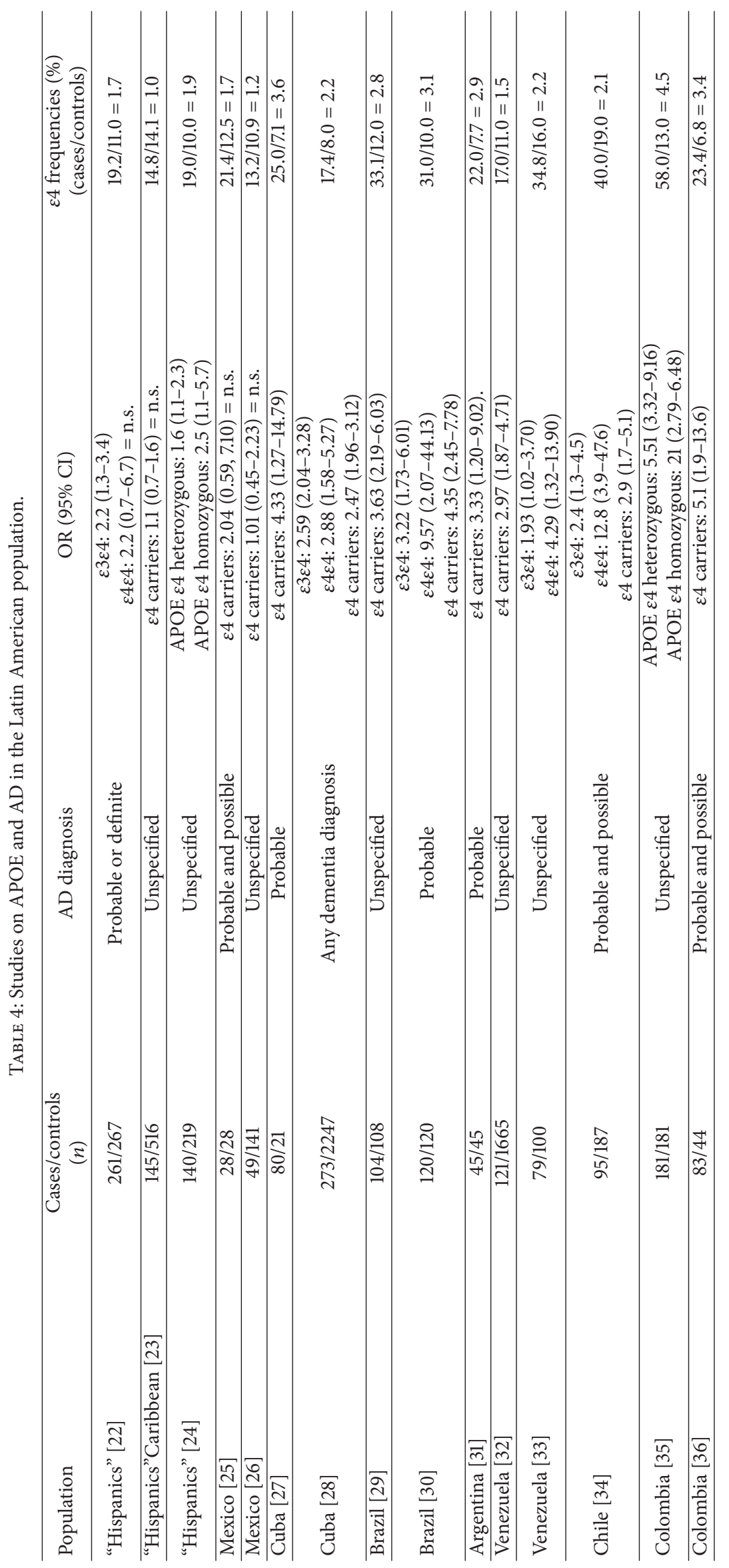




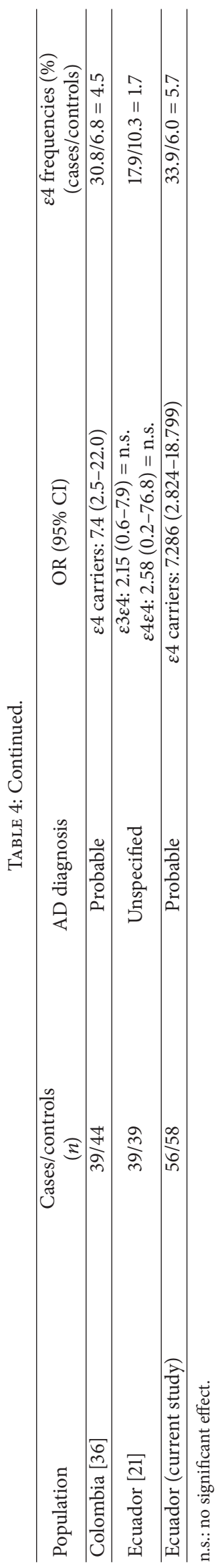


to the fact that the ancestry proportions of both countries range from predominantly Amerindian to predominantly European, with generally low levels of African descent [52].

Interestingly, the highest-risk associations between having one APOE $\varepsilon 4$ allele and LOAD described in Table 4 are those reported in patients with a diagnosis of probable AD as our study. This observation suggests a higher frequency of $\varepsilon 4$ in patients with a more accurate clinical diagnosis. The reasons could be either a subgroup of patients diagnosed with probable $\mathrm{AD}$ who could have an additional risk factor or another subgroup of patients diagnosed with possible AD who might not have the disease. Thus, the differentiation of this category should be taken into account when assessing the risk of APOE $\varepsilon 4$ allele for LOAD.

Importantly, it should be considered that Hispanics are a mixture of European, African, and Amerindian genomes, with percentages depending on the country of origin $[52,53]$. However, the term "Hispanic" is commonly incorrectly used because it tends to define any individual from the Caribbean, Central, and South America [53]. The ethnic diversity of the Hispanic subgroups is a consequence of their history. In the islands of the Caribbean, the native population was virtually extinguished after the coming of the Europeans. In the continent, two different native American empires, Mayas and Incas, were mainly concentrated in what now are Central America and Western South America, respectively [54]. At the beginning of the 16th century, the Inca Empire included today's Ecuador, Peru, Bolivia, and a large part of Chile, as well as smaller territories in Argentina and Colombia [55]. Currently, the Mestizo populations with the highest native ancestry are those located in areas which historically have had relatively large native populations [56]. Thus, the Ecuadorian Mestizo population has one of the largest Amerindian gene contributions among Hispanics [20]. Nevertheless, data often represents the Hispanic group as a whole ignoring the mentioned variability across the many subgroups, so it is possible that the differences in the ethnic composition of the Hispanic subgroups and the diversity within native American ancestors would be at least partially responsible for the different findings among Latin Americans. Altogether, these clearly indicate that a distinction across the Hispanic subgroups must be made when evaluating the implications of APOE $\varepsilon 4$ allele risk for LOAD. Also, there may be interactions between APOE and other genes, ethnic groups, and environmental factors that might alter the risk for $\mathrm{AD}$ conferred by the APOE $\varepsilon 4$ allele in different populations [8].

The relatively small size of the researched population should be mentioned with respect to our results as a limitation. Therefore, in order to overcome this limitation, patients were clinically diagnosed by a neurologist with probable AD using strict inclusion criteria according to NIA-AA and evidence of progressive cognitive decline so as to increase the level of clinical diagnosis certainty [37]. In addition, a careful selection of healthy controls was made through a neurological examination which discarded psychiatric and neurological impairments, and individuals with an MMSE score below 27 were excluded.

\section{Conclusion}

In conclusion, our results suggest that the APOE $\varepsilon 4$ allele is a strong risk factor for LOAD in the Ecuadorian Mestizo population. However, further research with a larger sample size is needed in order to confirm the level of risk and to determine the APOE $\varepsilon 4$ allele dose effect. Furthermore, we recommend studying the relationship between APOE $\varepsilon 4$ allele and the rapid progress of LOAD, the APOE $\varepsilon 4$ risk in other Ecuadorian ethnicities, and other genetic and environmental susceptibilities which could be regulating the predisposition to LOAD, as well as the conduction of prevalence and incidence $\mathrm{AD}$ studies on the Ecuadorian population. Finally, the control of different selected Hispanic subgroups should be taken into consideration when evaluating genetic contributions to LOAD risk, as these could directly affect the results.

\section{Conflicts of Interest}

The authors confirm that they have no conflicts of interest.

\section{Acknowledgments}

The authors are grateful to the patients and their relatives and the healthy volunteers for participating in this study. Also, they would like to acknowledge Arianne Llamos, M.D., for comments on the manuscript. This study was supported by Hospital de Especialidades de las Fuerzas Armadas $N^{\circ} 1$.

\section{References}

[1] Alzheimer's Association, "2017 Alzheimer's disease facts and figures," Alzheimers Dement, vol. 13, no. 4, pp. 325-373, 2017.

[2] M. Prince, A. Wimo, M. Guerchet, G. C. Ali, Y.-T. Wu, and M. Prina, "World Alzheimer Report 2015: the global impact of dementia: an analysis of prevalence, incidence, cost and trends," Tech. Rep., Alzheimer's Disease International (ADI), London, UK, 2015.

[3] Bupa and Alzheimer's Disease International, "Dementia in the americas: current and future cost and prevalence of alzheimer's disease and other dementias," Bupa and Alzheimer's Disease International, London, 2013.

[4] S. Baez and A. Ibáñez, "Dementia in Latin America: An emergent silent tsunami," Frontiers in Aging Neuroscience, vol. 8, article no. 253, 2016.

[5] R. Nitrini, C. M. C. Bottino, C. Albala et al., "Prevalence of dementia in Latin America: A Collaborative Study of Population-Based Cohorts," International Psychogeriatrics, vol. 21, no. 4, pp. 622-630, 2009.

[6] R. H. Takahashi, T. Nagao, and G. K. Gouras, "Plaque formation and the intraneuronal accumulation of $\beta$-amyloid in Alzheimer's disease," Pathology International, vol. 67, no. 4, pp. 185-193, 2017.

[7] B. T. Hyman, C. H. Phelps, T. G. Beach et al., "National Institute on Aging-Alzheimer's Association guidelines for the neuropathologic assessment of Alzheimer's disease," Alzheimer's \& Dementia, vol. 8, no. 1, pp. 1-13, 2012.

[8] C. Reitz and R. Mayeux, "Alzheimer disease: epidemiology, diagnostic criteria, risk factors and biomarkers," Biochemical Pharmacology, vol. 88, no. 4, pp. 640-651, 2014. 
[9] J. Hardy, "Amyloid, the presenilins and Alzheimer's disease," Trends in Neurosciences, vol. 20, no. 4, pp. 154-159, 1997.

[10] H. Lanoiselee, G. Nicolas, D. Wallon et al., "PSEN1, and PSEN2 mutations in early- onset Alzheimer disease?: A genetic screening study of familial and sporadic cases," PLoSMed, vol. 14, no. 3, p. 16, 2017.

[11] T. Jiang, J.-T. Yu, Y. Tian, and L. Tan, "Epidemiology and etiology of Alzheimer's disease: from genetic to non-genetic factors," Current Alzheimer Research, vol. 10, no. 8, pp. 852-867, 2013.

[12] D. Harold, R. Abraham, P. Hollingworth et al., "Genomewide association study identifies variants at CLU and PICALM associated with Alzheimer's disease," Nature Genetics, vol. 41, pp. 1088-1093, 2009.

[13] J.-C. Lambert, C. A. Ibrahim-Verbaas, and D. Harold, "Metaanalysis of 74,046 individuals identifies 11 new susceptibility loci for Alzheimer's disease," Nature Genetics, vol. 45, no. 12, pp. 1452-1458, 2013.

[14] C. Liu, T. Kanekiyo, H. Xu, and G. Bu, "Apolipoprotein e and Alzheimer disease: risk, mechanisms and therapy," Nature Reviews Neurology, vol. 9, no. 2, pp. 106-118, 2013.

[15] R. W. Mahley and S. C. Rall Jr., "Apolipoprotein E: far more than a lipid transport protein," Annual Review of Genomics and Human Genetics, vol. 1, no. 2000, pp. 507-537, 2000.

[16] J. E. Hixson and D. T. Vernier, "Restriction isotyping of human apolipoprotein E by gene amplification and cleavage with HhaI," Journal of Lipid Research, vol. 31, no. 3, pp. 545-548, 1990.

[17] L. Spinney, "Alzheimer's disease: The forgetting gene," Nature, vol. 510, no. 7503, pp. 26-28, 2014.

[18] Y. Huang, "Roles of apolipoprotein E4 (ApoE4) in the pathogenesis of Alzheimer's disease: lessons from ApoE mouse models," Biochemical Society Transactions, vol. 39, no. 4, pp. 924-932, 2011.

[19] R. Scacchi, R. M. Corbo, O. Rickards, E. Mantuano, a. Guevara, and G. F. De Stefano, "Apolipoprotein B and E genetic polymorphisms in the cayapa indians of ecuador," Hum. Biol. an Int. Rec. Res, vol. 69, no. 3, pp. 375-382, 1997.

[20] F. González-Andrade, D. Sánchez, J. González-Solórzano, S. Gascón, and B. Martínez-Jarreta, "Sex-specific genetic admixture of Mestizos, Amerindian Kichwas, and Afro-Ecuadorans from Ecuador," Human Biology, vol. 79, no. 1, pp. 51-77, 2007.

[21] C. Paz-Y-Miño, C. Carrera, A. López-Cortés et al., "Genetic polymorphisms in apolipoprotein e and glutathione peroxidase 1 genes in the ecuadorian population affected with Alzheimer's disease," The American Journal of the Medical Sciences, vol. 340, no. 5, pp. 373-377, 2010.

[22] L. A. Farrer, L. A. Cupples, J. L. Haines et al., "Effects of age, sex, and ethnicity on the association between apolipoprotein e genotype and alzheimer disease," The Journal of the American Medical Association, vol. 278, no. 16, pp. 1349-1356, 1997.

[23] M.-X. Tang, Y. Stern, K. Marder et al., "The APOE- $\varepsilon 4$ allele and the risk of Alzheimer disease among African Americans, whites, and Hispanics," Journal of the American Medical Association, vol. 279, no. 10, pp. 751-755, 1998.

[24] M.-X. Tang, G. Maestre, W.-Y. Tsai et al., "Relative risk of Alzheimer disease and age-at-onset distributions, based on APOE genotypes among elderly African Americans, Caucasians, and Hispanics in New York City," American Journal of Human Genetics, vol. 58, no. 3, pp. 574-584, 1996.

[25] M. Campos, S. D. Edland, and G. M. Peavy, "Exploratory study of apolipoprotein e $\varepsilon 4$ genotype and risk of Alzheimer's disease in Mexican Hispanics," Journal of the American Geriatrics Society, vol. 61, no. 6, pp. 1038-1040, 2013.

[26] J. M. Villalpando-Berumen, S. Mejia-Arango, C. A. AguilarSalinas, M. L. Ordonez-Sanchez, and L. M. Gutierrez-Robledo, "Apolipoprotein E ع4, Alzheimer's disease, and cognitive performance in elderly Mexican Mestizos," Journal of the American Geriatrics Society, vol. 56, no. 4, pp. 677-682, 2008.

[27] S. Sevush, G. Peruyera, F. Crawford, and M. Mullan, "Apolipoprotein-E $\varepsilon 4$ allele frequency and conferred risk for Cuban Americans with Alzheimer's disease," The American Journal of Geriatric Psychiatry, vol. 8, no. 3, pp. 254-256, 2000.

[28] B. M. Teruel, J. J. L. Rodríguez, P. McKeigue et al., "Interactions between genetic admixture, ethnic identity, APOE genotype and dementia prevalence in an admixed Cuban sample; a crosssectional population survey and nested case-control study," BMC Medical Genetics, vol. 12, article no. 43, 2011.

[29] C. M. B. E. de Bem, J. C. Pezzi, E. M. Borba et al., "The synergistic risk effect of apolipoprotein $\varepsilon 4$ and DNA (cytosine-5-)methyltransferase 3 beta (DNMT3B) haplotype for Alzheimer's disease," Molecular Biology Reports, vol. 43, no. 7, pp. 653-658, 2016.

[30] V. S. Bahia, F. Kok, S. N. Marie, S. O. Shinjo, P. Caramelli, and R. Nitrini, "Polymorphisms of APOE and LRP genes in Brazilian individuals with Alzheimer disease," Alzheimer Disease \& Associated Disorders, vol. 22, no. 1, pp. 61-65, 2008.

[31] L. Morelli, J. Leoni, E. M. Castano, C. A. Mangone, and A. Lambierto, "Apolipoprotein E polymorphism and late onset alzheimer's disease in argentina," Journal of Neurology, Neurosurgery \& Psychiatry, vol. 61, no. 4, pp. 426-427, 1996.

[32] A. E. Molero, G. Pino-Ramírez, and G. E. Maestre, "Modulation by age and gender of risk for Alzheimer's disease and vascular dementia associated with the apolipoprotein E- $\varepsilon 4$ allele in Latin Americans: Findings from the Maracaibo Aging Study," Neuroscience Letters, vol. 307, no. 1, pp. 5-8, 2001.

[33] E. de Mendonça, E. Salazar Alcalá, and M. Fernández-Mestre, "Role of genes GSTM1, GSTT1, and MnSOD in the development of late-onset Alzheimer disease and their relationship with APOE$^{\star} 4$," Neurología, vol. 31, no. 8, pp. 535-542, 2016.

[34] P. Quiroga, C. Calvo, C. Albala et al., "Apolipoprotein E polymorphism in elderly Chilean people with Alzheimer's disease," Neuroepidemiology, vol. 18, no. 1, pp. 48-52, 1999.

[35] J. Ortega-Rojas, L. Morales, E. Guerrero et al., "Association Analysis of Polymorphisms in TOMM40, CR1, PVRL2, SORL1, PICALM, and 14q32.13 Regions in Colombian Alzheimer Disease Patients," Alzheimer Disease \& Associated Disorders, vol. 30, no. 4, pp. 305-309, 2016.

[36] M. Jacquier, D. Arango, E. Villareal et al., "APOE $\varepsilon 4$ and Alzheimer's disease: Positive association in a Colombian clinical series and review of the Latin-American studies," Arquivos de Neuro-Psiquiatria, vol. 59, no. 1, pp. 11-17, 2001.

[37] G. M. McKhann, D. S. Knopman, H. Chertkow et al., “The diagnosis of dementia due to alzheimer's disease: recommendations from the national institute on aging-alzheimer's association workgroups on diagnostic guidelines for alzheimer's disease," Alzheimers Dement, vol. 7, no. 3, pp. 263-269, 2011.

[38] R. A. Hickman, A. Faustin, and T. Wisniewski, "Alzheimer Disease and Its Growing Epidemic: Risk Factors, Biomarkers, and the Urgent Need for Therapeutics," Neurologic Clinics, vol. 34, no. 4, pp. 941-953, 2016.

[39] R. M. Corbo and R. Scacchp, "Apolipoprotein E (APOE) allele distribution in the world. Is APOE* 4 a 'thrifty' allele?" Annals of Human Genetics, vol. 63, no. 4, pp. 301-310, 1999. 
[40] S. Crean, A. Ward, C. J. Mercaldi et al., "Apolipoprotein E $\varepsilon 4$ prevalence in Alzheimer's disease patients varies across global populations: A systematic literature review and meta-analysis," Dementia and Geriatric Cognitive Disorders, vol. 31, no. 1, pp. 20-30, 2011.

[41] A. Ward, S. Crean, C. J. Mercaldi et al., "Prevalence of Apolipoprotein E4 genotype and homozygotes (APOE e4/4) among patients diagnosed with alzheimer's disease: A systematic review and meta-analysis," Neuroepidemiology, vol. 38, no. 1, pp. 1-17, 2012.

[42] J.-Q. Li, L. Tan, H.-F. Wang et al., "Risk factors for predicting progression from mild cognitive impairment to alzheimer's disease: a systematic review and meta-analysis of cohort studies," Journal of Neurology, Neurosurgery \& Psychiatry, vol. 87, no. 6, pp. 476-484, 2016.

[43] V. Marca, O. Acosta, M. Cornejo-Olivas et al., "Polimorfismo genético de la Apolipoproteína E en una población peruana," Peru. Med. Exp. Salud Publica, vol. 28, no. 4, pp. 589-594, 2011.

[44] D. A. Demarchi, F. M. Salzano, M. E. Altuna et al., "APOE polymorphism distribution among Native Americans and related populations," Annals of Human Biology, vol. 32, no. 3, pp. 351365, 2005.

[45] O. Rickards, C. Martínez-Labarga, J. K. Lum, G. F. De Stefano, and R. L. Cann, "mtDNA history of the Cayapa Amerinds of ecuador: Detection of additional founding lineages for the native American populations," American Journal of Human Genetics, vol. 65, no. 2, pp. 519-530, 1999.

[46] R. Gamboa, G. Hernandez, R. Hesiquio et al., "Apolipoprotein E Polymorphism in the Indian and Mestizo Populations of Mexico," Hum. Biol, vol. 72, no. 6, pp. 975-981, 2000.

[47] V. M. Angulo, L. Esteban, P. Urbano, E. Hincapié, and L. A. Núñez, "Análisis del polimorfismo de APOE en la población de Barranquilla, Colombia," Biomédica, vol. 33, no. 4, p. 24, 2015.

[48] F. M. De Andrade, C. E. A. Coimbra Jr., R. V. Santos et al., "High heterogeneity of Apolipoprotein E gene frequencies in South American Indians," Annals of Human Biology, vol. 27, no. 1, pp. 29-34, 2000.

[49] L. U. Gerdes, C. Gerdes, P. S. Hansen, I. C. Klausen, O. Færgeman, and J. Dyerberg, "The apolipoprotein E polymorphism in Greenland Inuit in its global perspective," Human Genetics, vol. 98, no. 5, pp. 546-550, 1996.

[50] B. T. Hyman, E. T. Hedley-Whyte, G. W. Rebeck, J.-P. Vonsattel, H. L. West, and J. H. Growdon, "Apolipoprotein E $\epsilon 4 / 4$ in a Neuropathologically Normal Very Elderly Individual," JAMA Neurology, vol. 53, no. 3, p. 215, 1996.

[51] L. Bertram and R. E. Tanzi, "Thirty years of Alzheimer's disease genetics: the implications of systematic meta-analyses," Nature Reviews Neuroscience, vol. 9, no. 10, pp. 768-778, 2008.

[52] K. Bryc, C. Velez, T. Karafet et al., "Genome-wide patterns of population structure and admixture among Hispanic/Latino populations," Proceedings of the National Acadamy of Sciences of the United States of America, vol. 107, no. 2, pp. 8954-8961, 2010.

[53] F. M. Salzano and M. Sans, "Interethnic admixture and the evolution of Latin American populations," Genetics and Molecular Biology, vol. 37, no. 1, pp. 151-170, 2014.

[54] S. Collier, T. E. Skidmore, and H. Blakemore Cambridge University Press, New York, NY, USA, 1985.

[55] D.-T. Juif and J. Baten, "On the human capital of Inca Indios before and after the Spanish Conquest. Was there a "PreColonial Legacy"?" Explorations in Economic History, vol. 50, no. 2, pp. 227-241, 2013.
[56] S. Wang, N. Ray, W. Rojas et al., "Geographic Patterns of Genome Admixture in Latin American Mestizos," PLoS Genetics, vol. 4, no. 3, Article ID e1000037, 2008. 


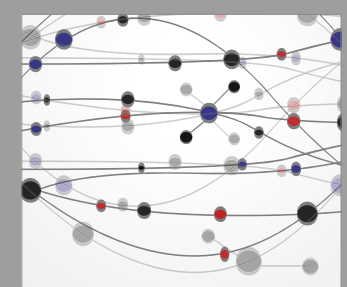

The Scientific World Journal
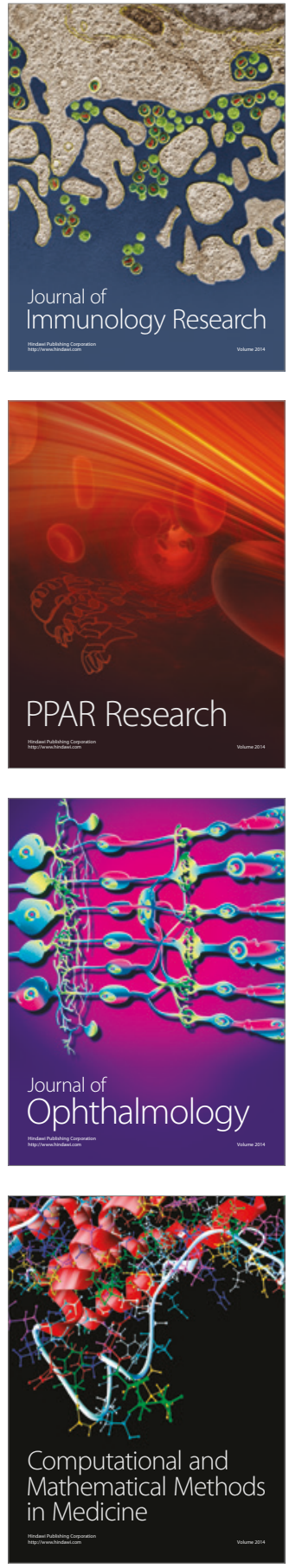

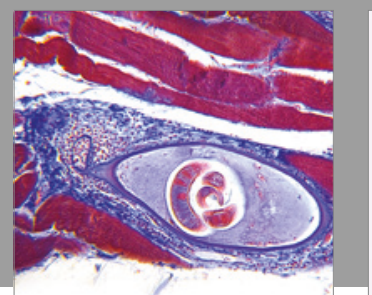

Gastroenterology Research and Practice
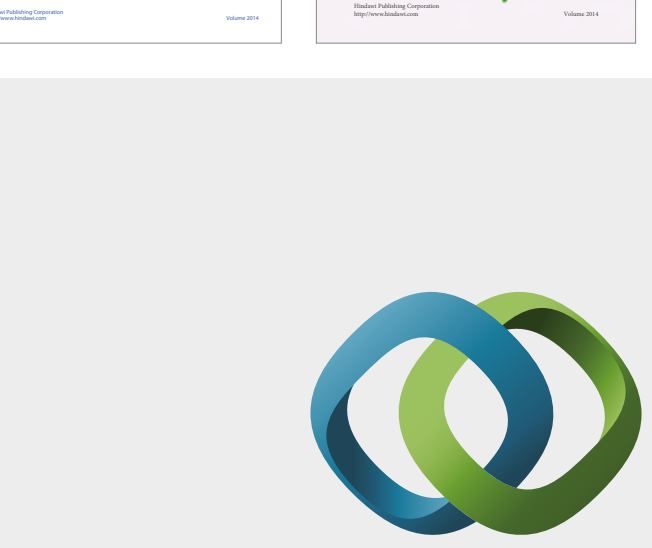

\section{Hindawi}

Submit your manuscripts at

https://www.hindawi.com
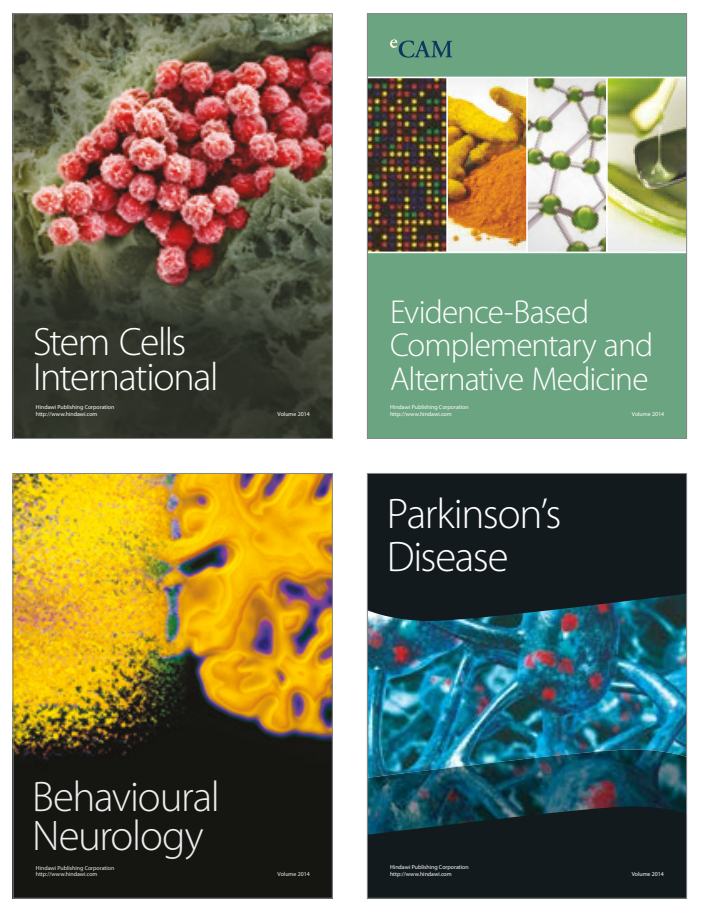
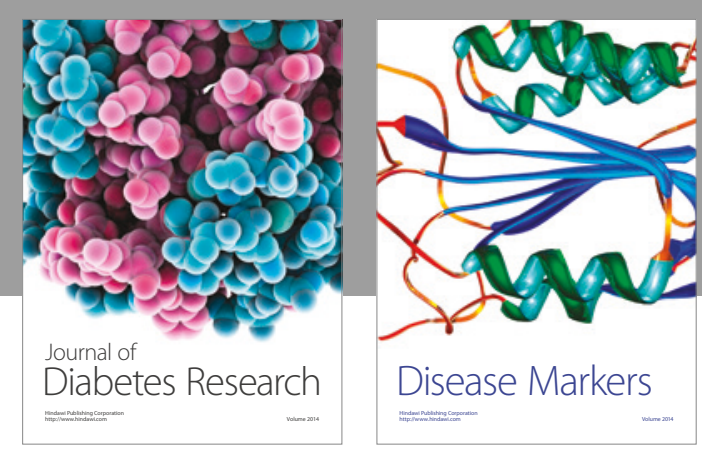

Disease Markers
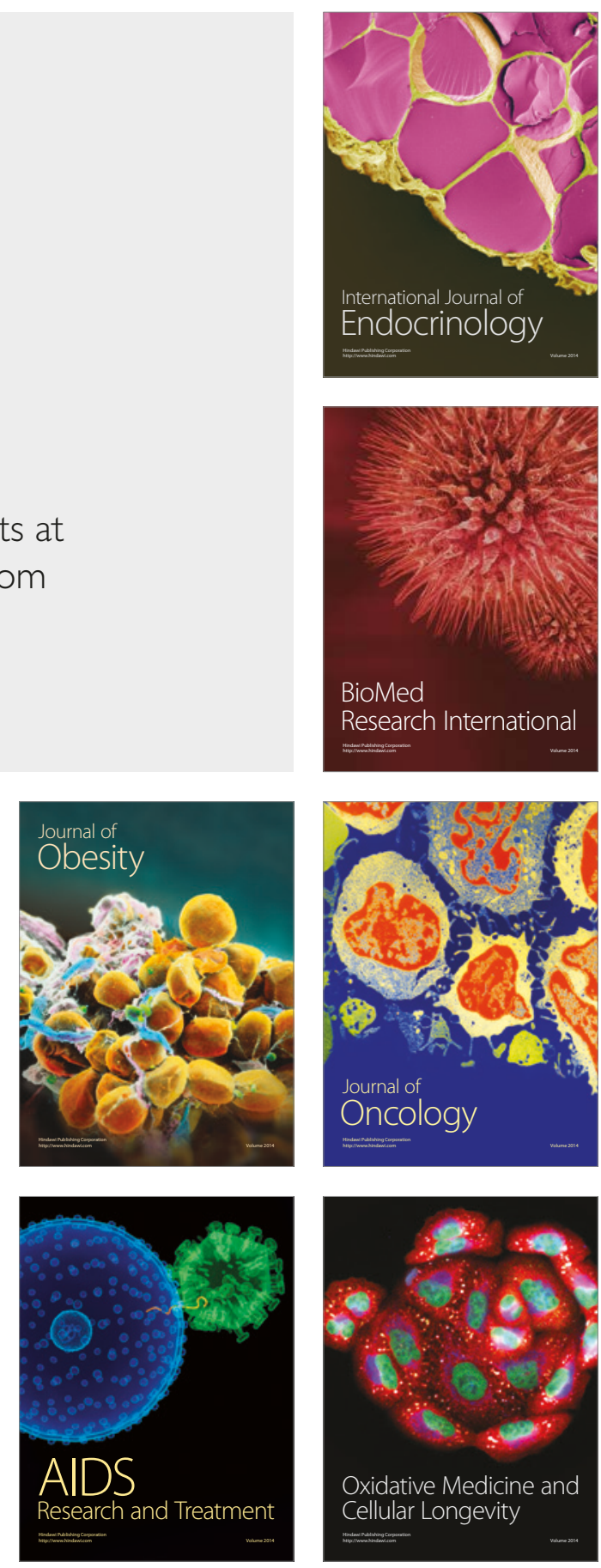